\title{
Identification of potential users of photovoltaic conversion
}

\author{
D. L. do Carmo ${ }^{1}$, R. C. Souza ${ }^{1}$ and M. N. Frota ${ }^{1}$ \\ ${ }^{1}$ Postgraduate Program in Metrology. Metrology for Quality and Innovation \\ PUC-Rio, Pontifical Catholic University of Rio de Janeiro \\ Marquês de São Vicente, 225. Gávea. Rio de Janeiro, RJ. (Brazil) \\ Phone/Fax number: +55 21 35271171, e-mail: reinaldo@ele.puc-rio.br, mfrota@puc-rio.br
}

\begin{abstract}
The growing demand for electricity resulted from the continuous technical progress and its disturbing impacts on the environment motivate the search for technological alternatives for sustainable energy generation. The power consumption changes from consumer to consumer and depends on the nature of the activity it performs. In general, activities of trade and industry consume more energy during business hours while residential buildings do at dusk and at night. With the exception of Saturdays, Sundays and holidays, period of greatest consumption of electricity in Rio de Janeiro is between $17 \mathrm{~h} 30$ and $20 \mathrm{~h} 30$. In summer months, the intensive use of air conditioning anticipates peak hours for $14 \mathrm{~h} 00$. When technically possible, the use of photovoltaic conversion in these peak times, therefore, constitutes a smart strategy for load shifting the peak hours to off-peak for large consumers with contract demand in medium and high voltage. This alternative has two impacts: it relieves the systems at peak times and allows the utility to defer investments in their installed infrastructure. This paper, while discussing the technical conditions and the benefits of using photovoltaic systems in Brazil, proposes a method to identify, based on local solarimetric conditions, the photovoltaic conversion potential users.
\end{abstract}

\section{Key words}

Photovoltaic conversion, load shifting, energy efficiency, solar radiation.

\section{Introduction}

Because of its geographic location, which provides excellent cycle of nature regarding to climatic aspects, Brazil has great potential for all renewable energies. The country has abundant resources of solar, wind, ocean and biomass allowing to maintain the renewable feature in the long run. Definitely a differential of the Brazilian electric matrix when compared to the global electric matrix.

Despite the widespread use of solar water heaters in inner cities, especially in rural areas, the share of the Sun in the national electric matrix is small [1]. Research indicates that was registered in the country in 2012 an installed capacity of only $17 \mathrm{MW}$ of photovoltaic [2].

As the basic parameter necessary to analyze the competitiveness of the use of solar photovoltaic systems the level of solar radiation, Brazil has a large advantage compared to many countries that make use of this technology. Records indicate that solar radiation in Brazil varies from 8 to $22 \mathrm{MJ} / \mathrm{m}^{2}$ during the day, with lower variations occurring from May to July, ranging from 8 to $18 \mathrm{MJ} / \mathrm{m}^{2}[3]$.

Thus, this paper proposes a methodology to identify and classify potential users of photovoltaic conversion. The methodology is based on the use of fuzzy logic to use information of energy consumption and solar radiation in order to make a final decision.

\section{Photovoltaics: a renewable alternative}

Much of the energy we use today comes from the sun, in form of light and heat. Wind energy is a consequence of the different heating of the Earth's atmosphere over the oceans and continents. Ethanol is the transformation of solar energy into organic matter derived from photosynthesis processes, like oil, natural gas and coal, which were formed thousands of years ago from plant residues, which derivate from photosynthesis and the Sun [4].

Photovoltaic systems convert solar energy directly into electricity. The photovoltaic modules, commercially available, are part of a reliable technology with a huge potential for growth all over the world. With a wide variety of types, sizes and conversion capacity, the facility can be designed for a single urban or rural residence, or even as large fields of generation that could supply many households. In many countries, policies and actions of fiscal and financial incentives provide funding for research, accelerating cost reductions, improve the efficiency of the panels and improvement of workforce, enabling the accelerated growth of the insertion of this type of energy source to the electric matrix [5].

\section{A. Brazilian Scene}

The participation of the Sun in the national electric matrix is small [1]. In 2012, the installed capacity of photovoltaic systems in Brazil was only $17 \mathrm{MW}$ [2]. 
With annual average of global irradiation between 1200 and $2400 \mathrm{kWh} / \mathrm{m}^{2} /$ year, Brazil has greater potential than major users of the technology, such as Germany, which has annual average of global irradiance in the range 900$1250 \mathrm{kWh} / \mathrm{m}^{2} /$ year [6]. The Brazilian Northeast is the region with the highest levels of solar radiation, surpassing even regions of the world that offer privileged solarimetric conditions, as the city of Dongola (located in the desert of Sudan) and the region of Dagget (located in the Mojave Desert, California) [1].

These data reveal that the photovoltaic conversion is a viable alternative to diversify the Brazilian energy matrix, despite still having small participation and not be taken into account in current sectorial balances [1].

\section{B. Characteristics of the photovoltaic market in Brazil}

The costs related to investments in photovoltaic systems have been falling at an accelerated rate. According to an article published by the Bloomberg website, in 2012 Brazil reached the "golden goal" grid parity (Fig. 1). This means that in some cases the use of photovoltaic systems to replace the conventional energy system becomes a good investment [7].

Nevertheless the falling prices for photovoltaic systems and equipment, the researches for exploitation of renewable energy has been increasing, making the excellent conditions of solar radiation in Brazilian territory an advantage. Anyway, the option for photovoltaic conversion is still not considered an attractive economic alternative in most cases. According to the Brazilian legislation [8], there are significant tax burdens that affects the use of this technology in the country. Tax on importation (II), tax on goods and services (ICMS), tax on industrialized products (IPI), tax for social interaction program (PIS), contribution to financing the social security (COFINS) and tax on services (ISS) are some of the taxes, impacting the costs associated to the required investment for the installation of

photovoltaic systems. These taxes impact about $25 \%$ in the internationally quoted prices [9].
The data provided by the Table I provide the minimum value of the energy supply to make the photovoltaic feasible, depending on the intended application and the characteristics of the system that was chosen.

Table I. - Cost level for use of photovoltaic systems

\begin{tabular}{|l|c|c|}
\hline \multicolumn{1}{|c|}{ CLASS } & POWER $(\mathrm{kWp})$ & $\begin{array}{c}\text { Leverage Cost for } \\
\text { Generation } \\
(\mathrm{R} \$ / \mathrm{MWh})\end{array}$ \\
\hline Residential & 10 & 541 \\
\hline Commercial & 100 & 463 \\
\hline Industrial & 1000 & 402 \\
\hline
\end{tabular}

\section{Incentive policies for photovoltaic conversion in} Brazil

The decree 5163/2004 encourages the purchase of electricity from distributed generation projects, which must be preceded by a public call directly promoted by the distribution agent. This decree is subject to a limit of $10 \%$ of the hire charge of the distribution agent and authorizes transfer to consumer tariffs up to the limit of the reference value, making the volume limitation does not impose further restrictions on the hiring of solar photovoltaics . Inhibits, however, the small photovoltaic array to find favorable economic environment, because he has to bear the high costs of technology transfer due to the transfer limitation [9].

Because of that ANEEL is studying proposals to reduce barriers of access to distribution systems, allowing the Public Consultation 15/2010 and Law 042/2011 Audience, which aimed for:

1) Public Consultation 15/2010: reduce existing regulatory barriers to connect small distributed generation to the distribution network [10].

2) Public Hearing 042/2011: to obtain contributions to the draft of Regulatory Resolution that seeks to reduce barriers to the installation of micro and mini generation distributed and change the discount on the Tariff for Use of the Distribution System (TUSD) and

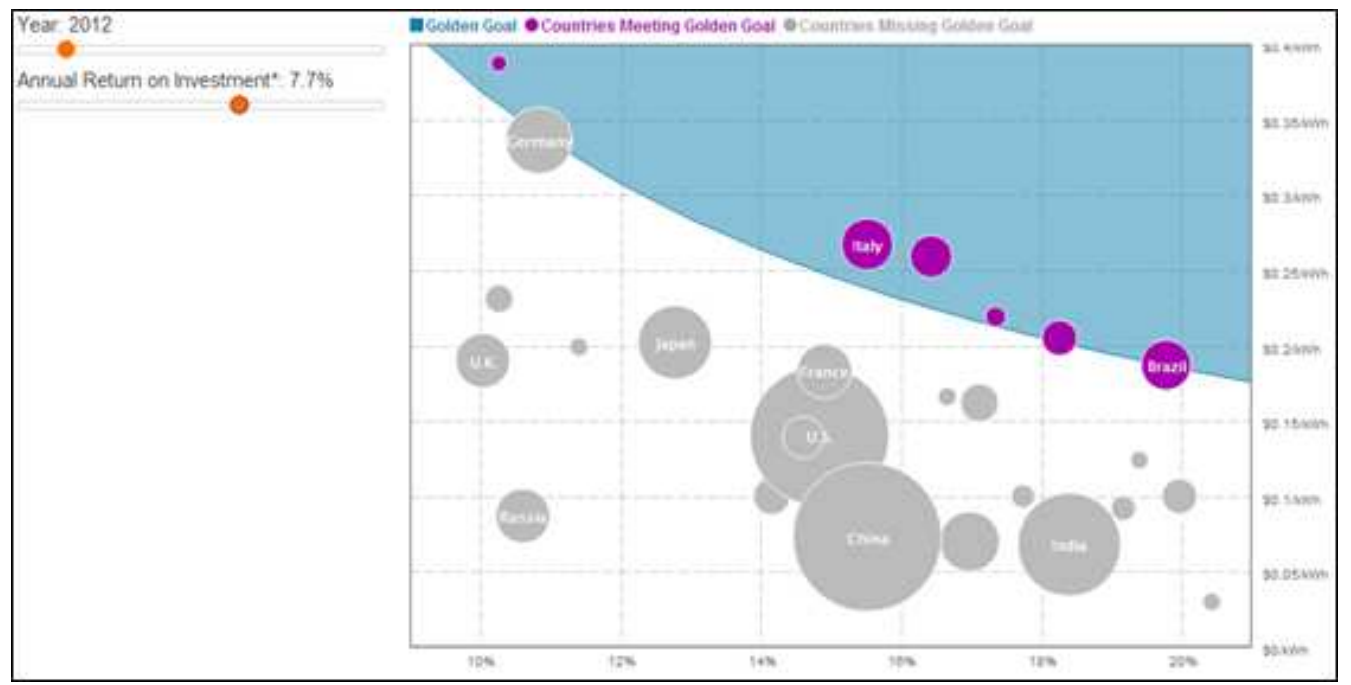

Fig. 1. Golden Goal Solar

Source: Roston, 2012 
the Tariff of Use of the Transmission System (TUST) for solar power plants [11].

To complement the actions, ANEEL made a public call concerning the R\&D Strategic Project 13/2011, which selected 17 photovoltaic projects totalizing $23.6 \mathrm{MW}$ to be installed in various regions of the country until 2015.

\section{Methodology of identification and classification}

The method is based on real measurements of power consumption of consumers with contracts in medium and high voltage (HV and MV), whose data was provided by the utility studied. Using these data and making use of Fuzzy Logic, load curves were constructed and compared with the curve of the incidence of local solar radiation of the same year constructed from official data provided by the governmental agency responsible for climate control, allowing to identify and classify technically qualified prospects to make use of photovoltaic conversion as an alternative source of power generation.

To follow regulatory requirements, billing performed by energy utilities is based on continuous measurement performed in each medium and large consumer unit. In case of the utility studied, this research had access to historical consumption measurements with period of 15 min of 4767 customers (from a total of approximately 8000) with contracts in MV and HV.

The global solar radiation data used refer to measurements performed by the National Institute of Meteorology (INMET), from the Automatic Meteorological Station of Agricultural Ecology Rio de Janeiro, located in Seropédica.

Before making use of the mass of data provided by the utility, these were adjusted to fix discrepancies and missing data, taking as a base the range of typical consumption. Such occurrences originate from flaws in the meter or power outages being common in the masses of data that have a large volume of information. Considering that such inconsistencies can compromise the analysis, statistical methods were used to make the proper treatment of so-called missing data and outliers.

\section{A. Fuzzy Logic}

A fuzzy inference system denotes a mapping or a function of a space of input alternatives to a space of output [12]. The basic idea of the theory of fuzzy sets is to represent a piece of information in a natural way in order to have the freedom to classify or solve a problem. While in Boolean Logic a set follows a restrictive domain determining welldefined sets, fuzzy logic allows intermediate values and the existence of partial pertinence, enabling a flexible way of information process available to, therefore, allow a more efficient analysis of concepts that cannot be quantified [13].

In light of classical set theory, a set $\mathrm{A}$ can be seen as a specific fuzzy set, usually called crisp $(X \rightarrow[0,1])$. A fuzzy set of the universe of discourse $\Omega$ is defined by a function of pertinence $(\Omega \rightarrow[0,1])$. This function assigns to each element $\mathrm{x}$ of $\Omega$ a degree to which $\mathrm{x}$ belongs to the specific fuzzy set [14].

The main objective of the fuzzy set theory is to treat the uncertainty information that concerns to ambiguous concepts. These vague concepts can be associated with variables that assume linguistic values instead of numbers. These variables are the basis for the approximate reasoning, which can be formalized by fuzzy inference systems. These systems work with a set of rules and can infer one or more outputs starting from the rules and facts presented as input [15].

The fuzzy system is outlined through its basic components:

1) Fuzzification: transforms the accurate inputs in fuzzy;

2) Fuzzy inference: determinates how the rules are activated;

3) Fuzzy terms: can be provided by experts or specified through a numerical bases;

4) Defuzzification: is used to provide accurate outputs.:

\section{B. Elimination of outliers}

Among the different tests used to find outliers, the Grubbs test was chosen. Studies conducted by [16] demonstrated that this test is more efficient, with uncertainty about $10 \%$ lower than the results obtained with the Dixon`s Q-test and about 3\% lower than those obtained with Chauvenet's criterion. The efficiency of the Grubbs test was also proven by [17], performing elimination of outliers successfully and showing excellent results.

The steps for the application of Grubbs test are described by [16] and, after they are followed, it is possible to perform the replacement of such outliers by the average of the previous measurement and the first measurement after the outlier, promoting its replacement by a nonbiased estimator.

\section{Elimination of missing data}

The large number of measurements allows more realistic results but the fact that these are performed automatically cause many failures in the measurement.

For treatment of missing data the multiple imputation method was used. This statistical method of substitution is effective because the results obtained with the bank completed by imputations are close to those obtained with the full set [18]. Thus, to apply the method, the missing data were identified and an average between the previous measurement and the first measurement after those was used for replacement.

The missing data were replaced by the average of the closer values, adapting the data set without 
compromising the actual customer consumption characteristics.

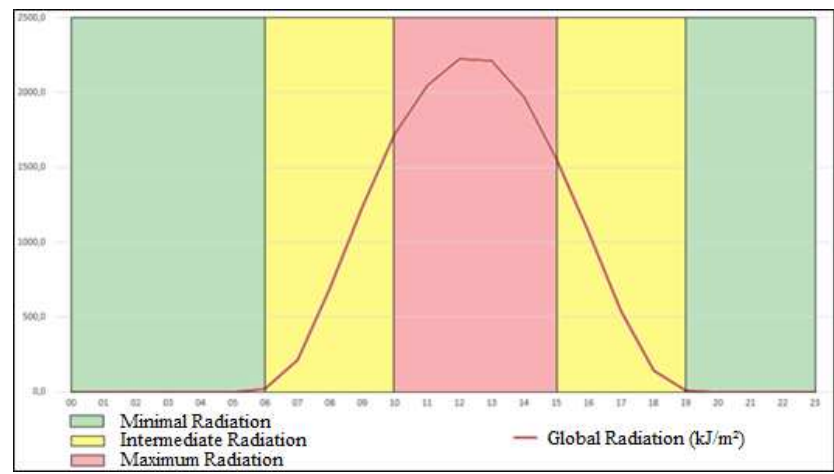

Fig. 2. Classification of the incident solar radiation spectrum

The input fuzzy sets were defined based on the results of descriptive statistics analysis of the energy consumption indicators (CI) for each level of incident radiation. These indicators were defined by the ratio between the average in the three intervals of radiation considered and the average of total consumption, as in (1), (2) and (3).

$$
\begin{array}{r}
C I \cdot \min =\mu_{\min } / \mu_{T} \\
C I{ }_{\text {int }}=\mu_{\text {int }} / \mu_{T} \\
C I . \max =\mu_{\max } / \mu_{T}
\end{array}
$$

Working with the identification and dividing the total range of each indicator into three equal parts was possible to predetermine three ranges.

Statistical analysis also identified the percentiles, offering an alternative classification for the estimators calculated. Thus, the value in the lowest quartile (25\% percentile), median $(50 \%$ percentile) and upper quartile $(75 \%$ percentile) are also qualified as threshold values to be used as range to classification of potential customers to make use of photovoltaic conversion.

Finally, the input fuzzy sets classification is determined from the superposition of the sets obtained in the statistical analysis and presented according to Table II

Table II. - Fuzzy sets of the energy consumption indicators

\begin{tabular}{|c|c|c|c|c|c|c|}
\hline CI & \multicolumn{2}{|c|}{$\begin{array}{c}\text { Minimal } \\
\text { Radiation }\end{array}$} & \multicolumn{2}{c|}{$\begin{array}{c}\text { Intermediate } \\
\text { Radiation }\end{array}$} & \multicolumn{2}{c|}{$\begin{array}{c}\text { Maximum } \\
\text { Radiation }\end{array}$} \\
\hline Low & 0 & 0.67 & 0 & 1.03 & 0 & 1.10 \\
\hline Medium & 0.58 & 1.33 & 0.61 & 1.25 & 0.87 & 1.74 \\
\hline High & 0.92 & 2 & 1.23 & 1.84 & 1.57 & 2.61 \\
\hline
\end{tabular}

Defined the categorization of fuzzy intervals, it is possible to plot the graphs of the input sets (Fig. 3).

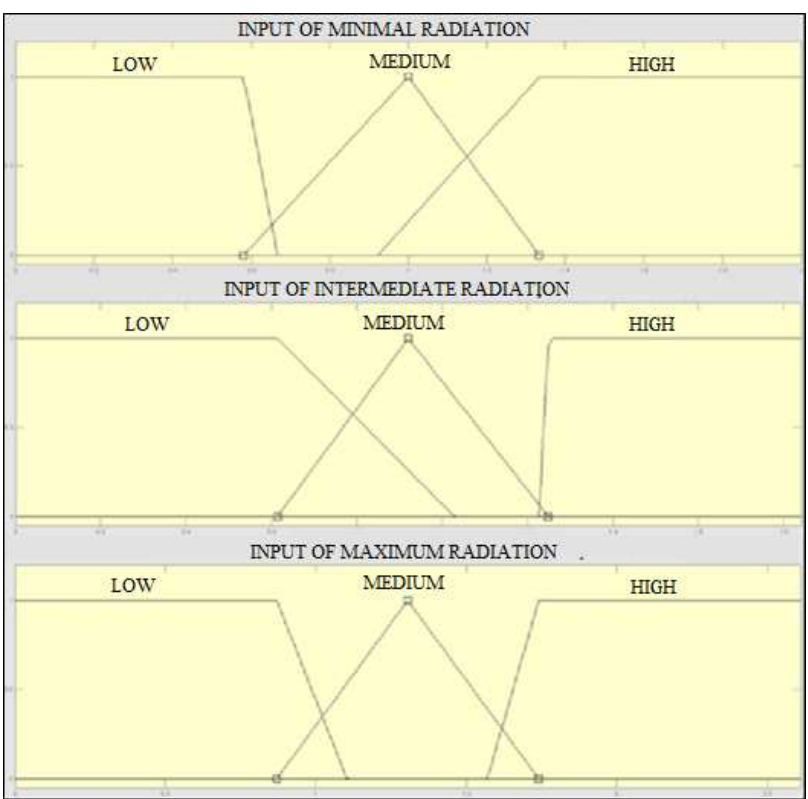

Fig. 3. Fuzzy sets of input

These inputs go through a set of predefined rules determined in a fuzzy inference system of Mamdani [19]. Souza et al (2013) defines that the fuzzy systems are formed by a set of rules that can be expressed by IFTHEN condition, which can be determined by experts or extracted numerical data [20].

The set of rules of the inference process aims to classify the users of the energy utility in five categories that reflect their potential to make use of photovoltaic systems. These categories are:

1) Category 1: costumer with a very low potential;

2) Category 2: costumer with low potential;

3) Category 3: costumer with a median potential;

4) Category 4: costumer with high potential;

5) Category 5: costumer with a very high potential.

With that was possible to plot the graph of membership function, show in Fig. 4.

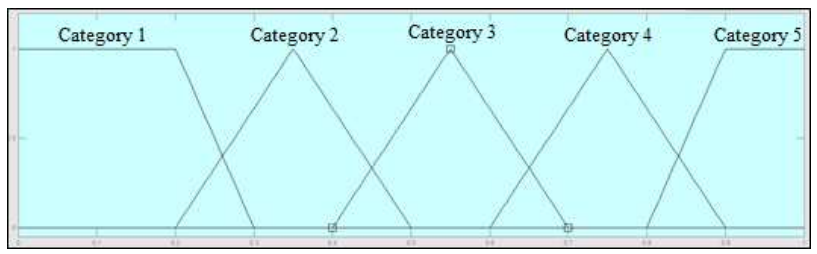

Fig. 4. Graph of membership function

The fuzzy inference process is executed resulting in fuzzy variables that are turned into crisp outputs the by defuzzification process. It generates results that allow the determination of the most appropriate membership degree for each category. The defuzzification method chosen was the Middle of Maximum (MOM), which calculates the average position of the group with the highest membership degree and allows instant adjustment the most representative category [21]. 
Thus, it was possible to classify customers according to the extracted outputs of the membership function, which is shown by the Table III.

Table III. - Fuzzy classification

\begin{tabular}{|c|c|}
\hline OUTPUT MOM & CLASSIFICATION \\
\hline 0.1 & Category 1 \\
\hline 0.35 & Category 2 \\
\hline 0.55 & Category 3 \\
\hline 0.7 & Category 4 \\
\hline 0.95 & Category 5 \\
\hline
\end{tabular}

\section{Results}

The potential assigned to a particular energy consumer to make use of photovoltaic conversion was evaluated from the mass of data processed, taking into consideration only aggregated values, preserving the confidentiality of personal information.

The survey`s results confirmed a population of large customers whose electricity consumption at times of maximum and intermediate solar radiation level characterize them as potential users of photovoltaic conversion.

Amongst the 4767 studied costumers just 2\% were classified in the Category 1 and $13 \%$ were classified in the Category 2. This means that just $15 \%$ of the users analyzed have no potential to use photovoltaic conversion when the main objective is the load shifting from peak hours to offpeak hours. Meanwhile, $85 \%$ of the costumers were considered with potential, of which $53 \%$ were classified as Category 3,11\% as Category 4 and $21 \%$ of Category 5 (Fig. 5).

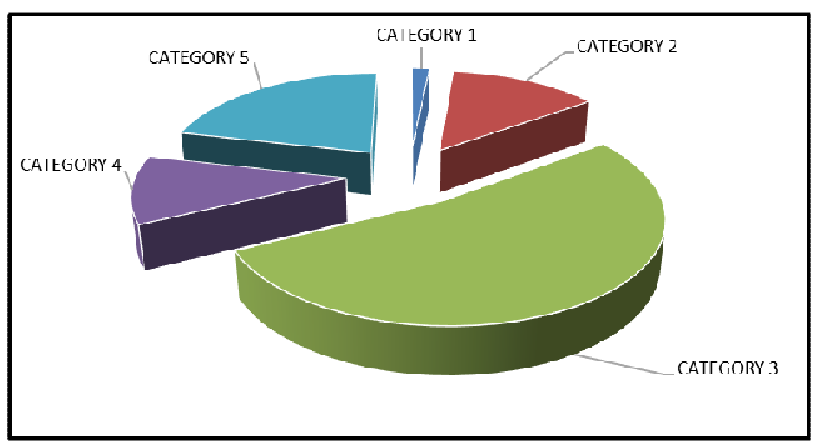

Fig. 5. Results from the methodology

\section{Conclusion}

This study of the use of alternative sources of energy interests to the local utility as an input to its strategic planning and to the Regulator as a backing for diversify the energy matrix.

The results were effective to indicate the technical feasibility to use photovoltaic conversion as an additional technological alternative for power generation. In addition, the research has shown that the methodology can be used as a decision support tool, helping the utility to identify potential customers who have interest in diversifying its consumption in peak hours, enabling the utility to delay investments without prejudice the quality of its services that today would not be admissible because of the pressure of the demand in peak hours consumption.

\section{References}

[1] ANEEL, Atlas de Energia Elétrica do Brasil, Brasilian Electricity regulatory Agency, Brasília (2008).

[2] EPIA, Global Market Outlook, European Photovoltaic Industry Association, Brussels (2013).

[3] UFPE, Atlas Solarimétrico do Brasil: banco de dados solarimétricos, Federal University of Pernambuco, Recife (2000).

[4] R. V. Ribas, Energia Renovável, University of São Paulo, São Paulo (2008).

[5] IEA, Energy Technology Initiatives, International Energy Agency, Paris (2013).

[6] EPE, Plano Decenal de Expansão de Energia 2022, Ministry of Mines and Energy, Brasília (2013).

[7] E. Roston, Solar Silicon Price Drop Brings Renewable Power Closer, Bloomberg, New York (2012). Acess: <http://go.bloomberg.com/multimedia/solar-silicon-price-dropbrings-renewable-power-closer/>

[8] L. L. M. Ortega, Conversão Fotovoltaica: comparação de modelos de desempenho, Pontifical Catholic University of Rio de Janeiro, Rio de Janeiro (2013).

[9] EPE, Análise da Inserção da Geração Solar na Matriz Elétrica Brasileira, Ministry of Mines and Energy, Rio de Janeiro (2012).

[10] ANEEL, Condições gerais de fornecimento de energia elétrica - RESOLUÇÃO NORMATIVA NO. 414/2010: direitos e deveres do consumidor de energia elétrica, Brasilian Electricity regulatory Agency, Brasília (2010).

[11] ANEEL, AVISO DE AUDIÊNCIA PÚBLICA Nº. 042/2011, Brasilian Electricity regulatory Agency, Brasília (2010).

[12] C. Lin, C. S. G. Lee, "Neural Fuzzy Systems: a neurofuzzy synergism to intelligent systems", Prentice-Hall, New Jersey (1996).

[13] L. A. Zadeh, "Fuzzy Sets", in Information and Control, Vol. 8, pp. 338-353.

[14] S. Sandri, C. Correa, "Lógica Nebulosa", in V Escola de Redes Neurais - ITA, pp. c073-c090.

[15] L. G. D. Melo, Sistemas Fuzzy Probabilísticos: Geração Automática De Regras E Defuzzificação Bayesiana, Federal Technological University of Paraná, Curitiba (2011).

[16] E. C. D. Oliveira, "Comparação das diferentes técnicas para exclusão de outliers", in Congresso da Qualidade em Metrologia. Rede Metrológica do Estado de São Paulo REMESP.

[17] J. L. Moreira, A. M. Marcos, P. Barros, "Proficiency Test on FTIR Wine Analysis", in Ciência Téc. Vitiv., pp. 41-51. 
[18] L. N. Nunes, M. M. Kluck, J. M. G. Fachel, "Uso da imputação múltipla de dados faltantes: uma simulação utilizando dados epidemiológicos", in Caderno de Saúde Pública, vol. 25, no.2, pp. $268-278$

[19] K. Tamás, L. T. Koczy, Mamdani-type Inference in Fuzzy Signature Based Rule Bases", in 8th International Symposium of Hungarian Researchers on Computation"',al Intelligence and Informatics, pp. 513-525.

[20] R. C. Souza, J. F. M. Pessanha, F. L. C. Oliveira, "A Residencial Consumer Payment Capability Index Based on Fuzzy Logic Inference", in Journal of Intelligent \& Fuzzy Systems 25, pp. 649-657.

[21] A. Mathews, Y. Osada, P, Brown, Fuzzy Logic, Canadian Society for the Study of Education, Ottawa (2010). 